\title{
DIREITO AO TRABALHO DA PESSOA COM DEFICIÊNCIA: DESAFIOS, CRISES E HORIZONTES
}

\section{PEOPLE WITH DISABILITIES'S RIGHT TO WORK: CHALLENGES, CRISES AND HORIZONS}

\author{
SIDNEI MACHADO ${ }^{1}$ \\ GABRIEL PERSEGONA SANTOS ${ }^{2}$
}

RESUMO: O artigo analisa os atuais contornos e impasses para a efetivação do direito ao trabalho das pessoas com deficiência no Brasil, propondo a superação do paradigma formal de atribuição de direitos. Apesar da ampla regulação normativa da proteção ao trabalho da pessoa deficiente, as reformas institucionais do direito do trabalho e da seguridade social impactam na eficácia desses direitos. Discute-se, portanto, a crise no discurso de tutela desses direitos no contexto das recentes reformas, tendo como quadro analítico principal a teoria crítica de Axel Honneth, tomando por base seu conceito de reconhecimento. Questiona-se em que medida a falta de reconhecimento do valor social do trabalho da pessoa com deficiência gera situações de injustiça e impacta na crise do discurso de atribuição de direitos. $\mathrm{O}$ texto apresenta, como horizonte para a construção de uma visão humana e emancipatória do trabalho, a perspectiva do direito ao trabalho como possível espaço de luta por reconhecimento e afirmação de direitos.

Palavras-chave: Axel Honneth; direito ao trabalho; pessoa com deficiência; reconhecimento.

\footnotetext{
${ }^{1}$ Professor Adjunto de Direito do Trabalho da Faculdade de Direito. É Professor Permanente do Programa de Pós-Graduação em Direito da Universidade Federal do Paraná (Capes 6). É Pesquisador e Líder do Grupo de Pesquisa Clínica de Direito do Trabalho (PPGD/UFPR). É colaborador do Programa de Pós-Graduação em Sociologia da UFPR. Doutorado em Direito (UFPR), com pos-doutorado na Université Paris Nanterre. Contato: sidneimchd@gmail.com.

${ }^{2}$ Mestrando em Direito das Relações Sociais pela Universidade Federal do Paraná (UFPR). Membro do Núcleo de Estudos em Direito Civil-Constitucional da UFPR - Virada de Copérnico e do grupo de pesquisa e extensão Clínica de Direito do Trabalho - Trabalho e Direitos. Contato: gabriel_percegona@hotmail.com
} 
ABSTRACT: The article analyzes the current contours and the difficulties for the realization of the right to work of people with disabilities in Brazil, proposing to overcome the formal paradigm of attribution of rights. In spite of the wide normative regulations which serve to protect the disabled person's right to work, it is noted that the institutional reforms of labor law and social security impact on the effectiveness of these rights. Therefore, the crisis in the discourse of protection of these rights is discussed in the context of recent reforms, having Axel Honneth's critical theory as the main analytical framework, based on his concept of recognition. It is questioned to what extent the lack of recognition of the social value of the work of people with disabilities creates situations of injustice, as well as how it impacts the crisis found in the discourse of attribution of rights. At last, the text presents, as a horizon for the construction of a human and emancipatory vision of work, the perspective of the right to work as a possible environment for the fight of recognition and affirmation of rights.

Keywords: Axel Honneth; labor law; people with disabilities; recognition.

\section{INTRODUÇÃO}

Este trabalho objetiva refletir sobre o direito ao trabalho da pessoa com deficiência sob as perspectivas dos desafios, crises e horizontes. Os desafios e as crises contextualizadas na análise, segundo o estado da arte desta relação e, os horizontes, a partir de uma visão prospectiva de adoção de uma nova compreensão que supere o paradigma formal do trabalho da pessoa com deficiência.

Os desafios centrais se dirigem à abordagem sobre a tutela da pessoa com deficiência no direito do trabalho. A construção desses direitos se dá, basicamente, sobre a recolocação da pessoa deficiente no centro de imputação das normas jurídicas, desafiando as pretensões de mercantilização do labor humano.

O direito ao trabalho, como direito humano e fundamental, é uma perspectiva apta a possibilitar ao deficiente o desenvolvimento de sua personalidade e inserilo qualitativamente no corpo social. Nesse aspecto, destacam-se o conteúdo e o alcance da proteção do texto da Constituição de 1988 em relação à pessoa com deficiência e, também, nos novos contornos normativos contidos no Estatuto da Pessoa com Deficiência de 2015 (Lei n. 13.146), e na Convenção de Nova Iorque, no Brasil incorporada em 2009 (Decreto n. 6.949/2009).

O espectro de crise, por outro lado, atinge a concepção positivada do direito ao trabalho da pessoa com deficiência. Constata-se uma dissonância entre o paradigma protetivo e o sentido das reformas trabalhistas e previdenciárias. As alterações normativas promovidas pela reforma trabalhista de 2017 (Lei n. 13.467/2017) e a reforma da previdência de 2019 (Emenda Constitucional n. 
103/2019), por via oblíqua, esvaziam e desconstroem os direitos das pessoas com deficiência.

O referencial analítico do reconhecimento numa versão da teoria crítica, a partir das reflexões de Axel Honneth sobre justiça e reconhecimento, serve como ferramenta de análise teórica para refletir sobre as alternativas ao modelo normativo de proteção. $\mathrm{O}$ texto da lei positivada não se revela suficiente para garantir os direitos, o que justifica a discussão da temática da proteção substancial e do reconhecimento. $\mathrm{O}$ texto propõe relacionar argumentos para superação da tutela formal em direção ao reconhecimento da pessoa com deficiência, numa perspectiva substancial de seus direitos.

\section{Pessoa COM DEFICIÊNCIA E DiREITO AO TRABALHO}

A análise do tratamento dado à pessoa com deficiência pressupõe precisões conceituais. Primeiro, deve-se ter como premissa que as abordagens não são homogêneas, ou seja, têm contornos definidos de acordo com cada cultura e temporalidade, pois o que existem são modelos ideais de representação da deficiência que, inclusive, podem conviver mutuamente.

Segundo, o tratamento dispensado à pessoa com deficiência refere-se a uma múltipla ordem de abordagens, que, não raro, divergem, conflitam e evidenciam o descompasso entre o tratamento normativo e o tratamento social.

Por fim, ao se referir a pessoa com deficiência, deve-se fazer menção a um sujeito concreto. Contudo, invariavelmente o conceito de "deficiência" genericamente compreendido acaba por abstrair o indivíduo de suas efetivas necessidades, que podem ser das mais variadas ordens.

Isso porque há deficiências de ordem física, mas também há disfuncionalidades de ordem psíquica, motora, emocional, o que justifica uma compreensão ampla da noção de deficiência. Os modelos ideais de abordagem da deficiência ao longo da história brasileira, indicam que uma primeira forma de se tratar a pessoa com deficiência é integrando-a à sociedade e à vida comunitária. A própria expressão "integrar" pressupõe um elemento externo, distinto daquilo a que se quer compatibilizar, que é um incorporar, trazer para dentro algo que estava fora. Havia um modelo padrão, tido como "normal", ao qual as pessoas "portadoras de deficiência ou necessidades especiais" deveriam se adequar, propiciando-lhes condições semelhantes às disponíveis para a generalidade das pessoas na sociedade (GIORDANO, 2000, p. 21-41).

As garantias e condições previstas no texto da Constituição brasileira de 1988, que visam à integração da pessoa com deficiência à sociedade, são a proibição de tratamento discriminatório pertinente a fixação de salários e critérios de admissão (art. 5\%, III e 6o, XXXI); a reserva de percentual de vagas em cargos e empregos públicos (art. 37, VIII); a garantia de benefício mensal no valor de um salário mínimo, quando comprovado não possuir meios de prover a própria manutenção 
ou através de sua família (art. 203, V); a adoção de critérios diferenciados para

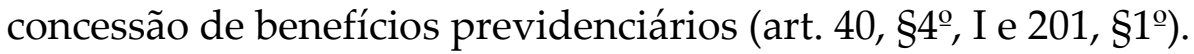

Para a tutela efetiva dos direitos das pessoas com deficiência é fundamental a superação desse paradigma que, em certa medida, ao imputar o ônus da adaptação à pessoa deficiente, acaba por vulnerá-la e excluí-la da sociedade. É fundamental a construção de um modelo de inclusão que, distinto do anterior, convoque a sociedade a participar e lhe conferir um papel ativo, que permita atender as necessidades das pessoas com deficiência (SASSAKI, 1997, p. 41). Na base desse novo paradigma estão as construções hermenêuticas do modelo social de deficiência, que se consubstanciou, normativamente, na Convenção Internacional Sobre os Direitos da Pessoa com Deficiência (CDPD).

O modelo social se caracteriza como uma ruptura paradigmática em relação ao modelo anterior de deficiência - o médico -, e advém especialmente do contexto de emergência, nas décadas de 1960 a 1980, de grupos minoritários que se mobilizaram e passaram a afirmar sua identidade e reivindicar direitos.

Com ênfase nas ideias de opressão social suportados por estes grupos, no discurso da multiculturalidade, e dando destaque às barreiras ambientais em detrimento de condições biológicas, "naturais", o cerne desse paradigma está na ideia de que as diferenças corporais, sensoriais ou intelectuais não constituem anomalias ou doenças (como pressupunha o modelo médico). Pelo contrário, qualificariam-se apenas como diferentes formas de vivência e existência (CANGUILHEM, 2009), e que se relacionariam intrinsecamente com outros elementos. Os problemas da pessoa com deficiência estão numa sociedade descapacitante que precisa mudar (BISOL; PEGORINI; VALENTINI; 2017, p. 94).

O modelo social de deficiência encontra-se consubstanciado nas considerações preambulares da Convenção de Nova York, que na alínea " $\mathrm{e}$ " reconhece que a deficiência é um conceito em evolução, resultante da interação entre a pessoa deficiente e as barreiras ambientais, que impedem a plena e efetiva participação dessas pessoas na sociedade em igualdade de oportunidades com as demais.

Há uma nova valoração sobre os direitos das pessoas com deficiência que se coaduna com a reconstrução dos fundamentos necessários à estruturação do paradigma do direito ao trabalho. Isso porque houve o esvaziamento do sentido do trabalho, ensejado pela modernidade capitalista, que acabou por reduzir o trabalho humano a uma forma peculiar de labor, que o subsume como produtor de valor para o capital, mas que não resulta em valor de uso para o trabalhador (WANDELLI, 2009, p. 6). Afasta-se o trabalho de sua percepção como direito, sendo necessário reaproximá-los por meio da refundamentação do direito ao trabalho à corporalidade dos sujeitos humanos em sociedade.

Portanto, uma primeira intersecção que se identifica é a concretude dos sujeitos, suas relações com o meio, suas necessidades e particularidades que devem ocupar posição central no direito. Neste ponto, destaca-se a necessidade de uma ruptura e alteração de paradigma em relação ao discurso sobre o corpo ou a corporalidade 
do trabalhador, precisamente pelo fato de que o objeto da sua prestação seria seu corpo, ou seja, este elemento se constituiria como a pedra angular do direito positivo do trabalho (SUPIOT, 1994, p. 54). Isso porque o corpo é o meio obrigatório para realização das obrigações assumidas pelo trabalhador.

No novo paradigma que se está a discutir, não se nega a importância da corporalidade. Ela, ao contrário, é ressaltada para afirmar que o trabalhador não é abstraído de sua concretude. $O$ trabalhador com deficiência pode possuir um corpo diverso, por meio do qual ao existir e trabalhar, se constitui. Essa ruptura se consolida a partir da observação dessa diversidade.

E isso exige outra compreensão sobre o direito ao trabalho que se pretende assegurar, como direito humano e fundamental a um trabalho que não se deve reduzir ao labor assalariado, distante do que se entende aceitável por um trabalho e uma vida digna. Deve-se superar a perspectiva de trabalho limitado às amarras impostas pelo modelo capitalista, que nega o livre desenvolvimento da corporalidade do trabalhador.

Portanto, a primeira barreira a ser ultrapassada diz respeito à realidade do trabalho capitalista, objetivante, opressor e desrealizador, que impossibilita a construção de um projeto de vida a partir do trabalho (WANDELLI, 2009, p. 25). Ou seja, deve-se refletir a partir da busca pela abertura dos sentidos do trabalho.

Trata-se de compreender as relações de trabalho como modos de realização das necessidades da vida, conciliando-as com princípios normativos que garantam essa realização. Em outras palavras, é preciso vislumbrar possibilidades de autorrealização e autovalorização do trabalhador por meio do trabalho, ainda que este seja uma mediação do capital. E o direito ao trabalho, institucionalmente concebido, possuiria um núcleo normativo que veicularia, no interior do sistema jurídico "na forma de um direito fundamental, os comandos jurídicos que afirmam esse potencial do trabalho em termos de realização das necessidades e de reconhecimento" (WANDELLI, 2009, p. 50).

Por mais que seja relevante esse aporte institucional, especialmente no campo jurídico, a plena realização do direito ao trabalho se dá a partir de transformações sociais. Contudo, mister se faz sua ressignificação para que seja colocado a serviço dos sujeitos, e não o contrário.

A partir dessas premissas é que se deve ler e compreender o sentido e o alcance do trabalho do deficiente presentes no texto da Convenção de Nova York e, em decorrência da sua regulamentação, pelo Estatuto da Pessoa com Deficiência.

A Convenção faz menção ao trabalho e emprego e o EPD contempla um específico capítulo contendo o direito ao trabalho. A primeira recomenda a necessidade de igualdade de oportunidade de acesso, remuneração e tratamento entre os trabalhadores com deficiência e os demais, bem como a proibição de discriminação. Esse direito abrange a oportunidade da pessoa com deficiência se manter com um trabalho de sua livre escolha ou aceitação no mercado laboral, em ambiente de trabalho que seja aberto, inclusivo e acessível. O EPD, por sua vez, 
prevê a liberdade de escolha do trabalho, em ambiente acessível e inclusivo, em igualdade de oportunidades. Além disso, incentiva a capacitação profissional, a proibição de discriminação, o fomento da habilitação e a reabilitação profissional, numa colocação competitiva (art. 37).

Em síntese, a forma pela qual o direito do trabalho regula o trabalho da pessoa com deficiência deve ser reconstruído sob dois pontos de vistas. O primeiro, referese ao reposicionamento do corpo, concebido como matéria e meio através do qual o sujeito se coloca no mundo e, por sua vez, se constitui. O corpo é a materialização da vida e, portanto, deve ocupar um locus privilegiado.

O segundo, exige a compreensão de que não basta a construção de um aparato normativo estéril, desconectado das múltiplas realidades. Ao contrário, demandase a construção de um direito que potencialize a realização subjetiva, a construção da personalidade a partir da percepção ampla do sentido de deficiência.

\section{A CRISE DO DIREITO DO TRABALHO}

O referencial analítico do reconhecimento, exposto por Charles Taylor, Axel Honneth e Nancy Fraser, cada qual com particularidades teóricas, revela a pretensão de repensar a teoria crítica a partir da necessidade de elaboração de um arcabouço conceitual para análise das estruturas de dominação reconfiguradas (FRASER; HONNETH; 2006).

Nancy Fraser compreende que os conflitos políticos pós-socialistas do fim século XX têm assumido a forma paradigmática de demandas pelo reconhecimento das diferenças - sob a perspectiva da nacionalidade, de raça, gênero e sexualidade - de modo que, nesta compreensão, a mobilização política passa a se articular a partir de identidades coletivas, em detrimento de interesses de classe. Fraser defende, contudo, que tais perspectivas (de identidade/diferença, dominação cultural/reconhecimento) devem ser compreendidas de maneira crítica e na medida em que possam ser coerentemente combinadas com a política social de igualdade construída sobre ideais de interesse, exploração e distribuição. Assim, a justiça se apresentaria sob uma perspectiva bidimensional, exigindo tanto reconhecimento (perspectiva cultural) como distribuição (ponto de vista econômico).

Nesse sentido, entende Fraser que o não reconhecimento é uma questão de impedimentos, externamente manifestados e publicamente verificáveis, a que certos indivíduos sejam membros integrais da sociedade (FRASER, 2007, p. 114). A justiça, então, se revela a partir de uma perspectiva abrangente e inclusiva, que concilia e torna complementares reconhecimento e distribuição.

Os paradigmas do reconhecimento e distribuição podem contrastar, contudo, sob três aspectos. Primeiro, ambos assumiriam concepções diferentes de injustiça socioeconômica, enraizada na estrutura econômica da sociedade, ou cultural, fincada em padrões sociais de representação, comunicação e interpretação. Além disso, propõem diferentes soluções para o problema da injustiça, seja pela reestruturação econômica ou pela mudança cultural ou simbólica. Por fim, aderem 
a diferentes concepções acerca das coletividades que sofrem injustiças, tomando-as como classes que se definem economicamente por uma relação característica com o mercado, ou como meios de produção, ou como grupos que possuem menor respeito, estima e consideração.

Fraser apresenta como potenciais de modificação do status quo as noções de afirmação, que se realiza com a correção dos resultados indesejáveis sem o rearranjo social, e transformação, concretizada com a correção dos resultados injustos pela reestruturação dos elementos que os produzem. Segundo ela, os remédios afirmativos são tendentes à produção de diferenciação de grupo, enquanto os transformativos tendem a desestabilizar ou negar diferenciações. $\mathrm{Na}$ resposta à dualidade afirmação versus transformação, a filósofa concebe as "reformas não reformistas" como solução.

Essas reformas captam identidades e satisfazem algumas necessidades dentro dos marcos de reconhecimento e distribuição vigentes. Empreendem, ainda, mudanças que, com o tempo, são capazes de abrir espaço às reformas mais radicais, associadas à reparação transversal - medidas distributivas para remediar o reconhecimento errôneo e a desigualdade.

Em síntese, as reformas não reformistas, ou anticapitalistas, seriam capazes de conciliar as demandas cotidianas mais comuns dos trabalhadores com reivindicações mais amplas, permitindo a superação da dicotomia entre reforma e revolução (SILVA, 2017). Essas reformas atuam numa direção contra sistêmica, por conterem o potencial disruptivo em relação ao capital e ao poder de classe. Nesse sentido, elas não devem focar exclusivamente na produção e no trabalho remunerado, mas necessitam, igualmente, tratar da organização social que envolve a reprodução (a existência individual e coletiva, portanto). Conforme se verá a seguir, estes são pressupostos que também encontram acolhida na teoria crítica honnethiana.

Diferentemente de Fraser, Axel Honneth não concebe o dualismo existente entre redistribuição e reconhecimento, mas entende que as experiências de injustiça são um contínuo de formas de negação do reconhecimento, que podem ocorrer em suas três esferas ou princípios: amor, lei e conquista ("logro"). As relações de amor são fundamentais para a estruturação da personalidade dos sujeitos e se desenvolvem durante a primeira infância. As relações de direito possibilitam que os indivíduos se reconheçam reciprocamente como seres humanos dotados de igualdade. Por fim, as relações de conquista ou mérito, permitem o reconhecimento comunitário das capacidades e habilidades de cada ator social.

Contudo, aos três princípios do reconhecimento, Honneth associa, respectivamente, formas típicas de desrespeito. Destaca, primeiro, aquelas que atingem a integridade psicofísica dos sujeitos em desenvolvimento e, assim, sua autoconfiança básica; em seguida, a negação e retirada de direitos, reduzindo a possibilidade de autorrespeito e, portanto, o sentimento de igualdade; a última 
forma de desrespeito estaria contida na referência negativa ou não valorização de certos indivíduos ou grupos, afetando a autoestima subjetiva.

De fato, existe uma intensa relação entre reconhecimento e desrespeito. $\mathrm{O}$ último se mostra não como um reconhecimento potencial, ainda não alcançado, mas como negação daquilo que havia intersubjetivamente se adquirido nas três esferas indicadas - autoconfiança (esfera do amor), autorrespeito (esfera do direito) e autoestima (esfera da conquista).

Para Charles Taylor, o reconhecimento se configura como uma necessidade humana vital, sendo que sua negação não corresponde apenas a uma demonstração de desrespeito, mas contém em si uma consequência grave, que é a de diminuir a capacidade que a pessoa tem de construir sua autoestima (TAYLOR, 1994, p. 25).

Sob esta perspectiva, o reconhecimento do valor do trabalho do sujeito para sua comunidade acaba por constituir sua autopercepção e auto imagem consigo e em relação à sociedade. Neste sentido, "um indivíduo só é capaz de respeitar-se a si mesmo de um modo integral quando, no quadro da distribuição objetivamente dada de funções, pode identificar a contribuição positiva que ele traz para a reprodução da coletividade" (HONNETH, 2003, p. 150). Em outras palavras, é o olhar do outro, realizado por meio do reconhecimento sobre o trabalho desempenhado pelo sujeito, que constitui sua identidade.

A desregulação e flexibilização promovidas pelas reformas trabalhistas e previdenciárias, a partir de 2017, fragilizam a garantia de direitos dos trabalhadores mais vulneráveis, dentre eles da pessoa com deficiência, aumentando a tensão do discurso de inclusão e proteção.

A regulamentação do teletrabalho é um exemplo emblemático. Em uma primeira análise, essa forma de trabalho poderia se apresentar compatível com a perspectiva de inclusão e garantia do trabalho à pessoa deficiente, uma vez que permitiria que um maior número de deficientes ingressasse no mercado de trabalho formal.

Contudo, a prática demonstra que o teletrabalho, que ocorre fora da empresa por meios telemáticos que viabilizam a sua realização de forma remota, acaba por possibilitar que se intensifique os mecanismos de controle da empresa e se extrapole com habitualidade o limite de jornada diária de oito horas, produzindo notoriamente condições precárias de trabalho, com o potencial de repercutir em agravos físicos e psicológicos do deficiente.

O teletrabalho de fato poderia ser uma ferramenta de inclusão por se dar diretamente na residência do empregado deficiente, mas pode também se prestar a uma estratégia de inclusão formal da pessoa com deficiência. Ao trabalhar em sua residência, se retiraria da pessoa qualquer possibilidade de convivência com seus pares e, em virtude disso, haveria um reconhecimento deficitário ou mesmo ausente. Sob a perspectiva inversa, daqueles que trabalhariam no estabelecimento seria retirada a oportunidade de vivenciar uma sociabilidade plural. Sendo justamente sob esta perspectiva relacional sobre a qual se funda a noção de 
reconhecimento, a partir do momento em que se suprime essa esfera, perde-se parte do potencial realizador do contato interpessoal.

Outro exemplo que demonstra a crise do discurso dos direitos é o trabalho pela modalidade o contrato de trabalho intermitente, instituído na reforma trabalhista de 2017 (artigo 443 da CLT), e que cria a possibilidade de que o empregado ostente, concomitantemente, diversos vínculos formais, mas não assegura um trabalho digno, já que não garante sequer o pagamento do salário mínimo mensal.

Além disso, o trabalho intermitente pode ser um novo espaço de fraude à lei de cotas para pessoa com deficiência, que determina a reserva de um percentual de vagas em empresas. $\mathrm{O}$ vínculo formal existiria para os fins legais, de cumprimento das cotas, de modo que a pessoa com deficiência que labore sob o contrato de trabalho intermitente é tida como trabalhadora com emprego ativo, ainda que trabalhe sob demanda poucas horas por mês, com reduzida remuneração.

Por fim, já no âmbito da proteção previdenciária, destacam-se as recentes tentativas de se reduzir o valor do Benefício de Prestação Continuada - BPC, ponto polêmico da reforma da previdência. O BPC (Lei n. 8.742/1993) garante um saláriomínimo mensal à pessoa com deficiência e ao idoso com 65 (sessenta e cinco) anos ou mais que comprovem não possuir meios de prover a própria manutenção nem de tê-la provida por sua família. Apesar de não ter sido recepcionada pela Emenda Constitucional 103/2019, o discurso e o projeto para a redução do benefício, por si só, revelam o desrespeito e a ausência de reconhecimento da pessoa com deficiência como sujeito que titulariza direitos.

Em relação à pessoa com deficiência, a Emenda Constitucional 103/2019 apenas consigna, sobre o direito à aposentadoria que, enquanto a lei não regule a aposentadoria da pessoa com deficiência assegurada no Regime Geral de Previdência Social ou do servidor público federal com deficiência vinculado a regime próprio de previdência social, ela será concedida na forma da Lei Complementar $\mathrm{n}^{\mathrm{o}}$ 142, de 8 de maio de 2013, inclusive quanto aos critérios de cálculo dos benefícios (artigo 22 da Emenda Constitucional 103).

\section{RECONHECIMENTO COMO HORIZONTE}

No trabalho que se desenvolve sob o modelo de produção capitalista, há perda da identidade entre o trabalhador e o fruto de seu labor. Aquele direciona sua força produtiva à realização de uma atividade que se distancia de sua essência, ou seja, é um agir muitas vezes mecânico e reprodutivo. A noção emancipatória do trabalho se esvazia frente a busca pelo lucro e pela produtividade.

Honneth (2008, p. 46), ao discutir o trabalho contemporâneo, subdivide a população economicamente ativa em três grupos: aqueles que lutam para ter acesso a alguma ocupação que the assegure a subsistência, os que realizam suas atividades em condições precariamente protegidas e altamente desregulamentadas e, por fim, os que experimentam rápida desprofissionalização e terceirização de seus postos de trabalho. 
Para Honneth, pouco se discutiu sobre o valor emancipatório e humano do trabalho, marginalizando as discussões sobre a produção, na medida em que a teoria crítica da sociedade pareceu ocupar-se prioritariamente com questões relativas à integração política e aos direitos de cidadania, sem se debruçar sobre as ameaçadas conquistas na fase da produção (HONNETH, 2008, p. 47). É possível compreender que o desrespeito ao mérito do trabalho individual se insere na intersecção entre um trabalho que se desnatura e dissocia do trabalhador, e uma teoria crítica que se afasta de problematizar a ausência de trabalho emancipatório.

O trabalhador, pelo modo de produção capitalista, é visto e tratado como mais uma peça integrante da cadeia produtiva. Seu tempo, seus movimentos e suas ações são padronizados, voltados à maximização da produção e, assim, do lucro. $\mathrm{O}$ sujeito se aparta do produto de seu trabalho, que é visto, no modelo de que se trata, quase como um objeto autopoiético numa cadeia produtiva serial.

Via de consequência, se o objeto existe a despeito do sujeito, o trabalhador não tem seu agir valorizado, ou seja, não tem seu mérito e sua competência reconhecidos. Por outro lado, a dessubjetivação do processo produtivo acaba por fazer com que o trabalhador, por si próprio, não se reconheça como parte fundamental e imprescindível desse modo de produção.

Em se tratando de pessoas com deficiência, isso se torna ainda mais acentuado. O trabalhador deficiente, para além de todo esse processo de esterilização produtiva, precisa se reconhecer como integrante do corpo do local em que labora, e por seu trabalho ser valorizado por seus pares o que, em muitas situações, pelo estigma que carregam, se torna ainda mais difícil.

Não se reconhecendo como elemento integrante da cadeia de trabalho, o sujeito também deixa de se perceber como parte de um grupo de trabalhadores que podem se articular, defender seus interesses e exigir respeito e consideração. É possível concluir que o desrespeito e a falta de reconhecimento do valor do trabalho dos indivíduos acabam por desarticulá-los e inibi-los a resistir contra essa forma de injustiça.

Esses fatores ajudam a entender a crise do direito do trabalho a que se aludiu acima. Os trabalhadores buscam o trabalho para garantir a subsistência, mas também a satisfação individual pela atividade realizada (HONNETH, 2008, p. 47). Ao se deixar de reconhecer o valor do trabalho humano, cada vez mais recorrentemente substituído ou dependente de novas tecnologias, há uma menor autopercepção do trabalhador de que seja um indivíduo indispensável ao sistema, e dotado de direitos e valores. Sem o reconhecimento, em verdade, a vítima permanece invisível, e o desrespeito e a injustiça não podem ser vivenciados como uma experiência mobilizadora (WANDELLI, 2009, p. 185).

O capital e seus agentes, atuando em seu interesse, retiram do trabalhador sua auto-compreensão. Ao não se identificar como uma pessoa que titulariza direitos, sem opor resistência, torna-se muito mais simples a retirada do suporte normativo 
que tutela os trabalhadores. O que remanesce, no campo dos direitos, se torna mero texto, com pouco ou nenhuma efetividade.

O discurso estéril e abstrato de direito, sem a respectiva e substancial materialidade, acaba por alçar a pessoa com deficiência a um patamar de igualdade formal, em que suas peculiaridades deixam de ser consideradas, dando lugar a um espaço de negação de direitos.

É insuficiente afirmar que a pessoa com deficiência tem direito a determinado número de vagas numa empresa se, por uma mudança legislativa, ele é subtraído, seja por mecanismos que facilitam fraudar essa sistemática, seja pela impossibilidade de realização plena de direitos.

Assim, o discurso garantista de direitos com base no texto da lei não é suficiente à efetivação do direito ao trabalho, como direito humano e fundamental da pessoa com deficiência. E essa inconstância e oscilação se dá por fatores de ordem política, econômica, social, religiosa e, em certa medida decorrente de todas elas, de ordem jurídica.

Como superar essa perspectiva formal de direito em direção a um tratamento, de fato, realizador das potencialidades humanas? Em outras palavras, pensar a reformulação das relações de trabalho? Para Wandelli (2009, p. 178), o reconhecimento em relação ao trabalho dos sujeitos, é expressado em dois momentos. O primeiro deles se dá com a apreciação da utilidade social da conduta do trabalhador, enquanto o segundo diz respeito à avaliação feita em relação ao resultado do trabalho. A potencialidade na construção de sentido e na autorrealização pelo trabalho revela-se de fundamental importância para o preenchimento do conteúdo material do direito ao trabalho, como dotado de fundamentalidade, tendo em vista esta propensão constitutiva.

A questão que se impõe diz respeito à realização desse compromisso do reconhecimento frente ao modelo capitalista do trabalho, uma vez que quanto mais valorizada a dinâmica do capital, mais se desvaloriza a realização das necessidades da corporalidade humana e mais precário é o reconhecimento de quem vive do trabalho (WANDELLI, 2009, p. 184).Por meio do direito ao trabalho, que contém em si a potencialidade de realização de condutas de luta pela sua efetivação, é possível a ampliação dos direitos.

Nestes termos, o reconhecimento, além de constituir importante fonte de legitimação, é fator relevante e indispensável ao processo de inclusão e de atribuição e garantia de direitos à pessoa com deficiência, e, mais significativamente, no âmbito do direito ao trabalho.

São, portanto, três esferas por meio das quais os indivíduos podem buscar reconhecimento recíproco e que se entrelaçam com maior evidência. Primeiro, destacam-se as relações íntimas, inicialmente familiares e depois educacionais, fortemente marcadas por práticas afetuosas através das quais passa-se a se conceber como sujeito com necessidades próprias. Na segunda esfera, a jurídica, as relações são pautadas na igualdade de direitos mutuamente outorgados e, a partir 
disso, há a autocompreensão de que as pessoas são dotadas da mesma autonomia (BRAGA; SCHUMACHER; 2013, p. 378). Por último, existem as relações sociais, em que se percebem como sujeitos dotados de características, habilidades e talentos valorados positivamente no seio social.

É na intersecção dessas esferas que, em termos ideais, deve-se operar o correto reconhecimento, que se configura em "dispositivos de proteção intersubjetiva que asseguram as condições de liberdade objetiva e subjetiva" (HONNETH, 2009, p. 274). Por liberdade objetiva, entende-se a ausência de coerção ou qualquer outra forma de retesamento externo; por sua vez, a liberdade subjetiva se configura na inexistência de bloqueios internos, inibições de ordem anímica. A autonomia intersubjetiva depende, por pressuposto, das relações intersubjetivas de mútuo respeito e consideração.

Desta forma, o reconhecimento representa as condições que permitem aos sujeitos modalidades de autorrelação positiva, possibilitando autoconfiança, autorrespeito e autoestima, núcleos para a percepção de um sentimento interno de autonomia que o próprio agente desenvolve e vivência (BRAGA; SCHUMACHER; 2013, p. 381-382).

Quanto maior o respeito a uma pessoa, maior o cômputo de sua esfera de liberdade. Neste ponto, o reconhecimento social tem poder de amoldar as construções jurídicas, não apenas no momento de criação, mas de concretização de suas disposições, sendo importante elemento para a refundação do direito do trabalho.

Entende-se que a perspectiva do trabalho, concebido como elemento emancipador e integrante da esfera subjetiva do indivíduo, e como direito, tem o potencial de recolocá-lo no centro de imputação das normas jurídicas, fazendo-se perceber como integrante do corpo produtivo e, assim, ver-se como titular de respeito e consideração por seus pares.

\section{CONSIDERAÇÕES FINAIS}

A regulação da proteção da pessoa com deficiência, apesar do amparo no texto constitucional, no Estatuto da Pessoa com Deficiência e na Convenção de Nova York, não é suficiente para garantir a efetividade do direito ao trabalho da pessoa deficiente.

O direito ao trabalho pressupõe um trabalho próprio que é o da produçãoconsumo, inserido na lógica capitalista, com potencialidades de encampar campos de luta por direitos fundamentais na óptica do trabalho humano.

As reformas institucionais do trabalho, no campo do direito do trabalho e do direito previdenciário, têm o potencial de cristalizar e intensificar a vulnerabilidade dos direitos da pessoa com deficiência, a exemplo das modalidades de teletrabalho e do trabalho intermitente.

A noção de reconhecimento (Honneth) permite compreender outros elementos da crise do direito ao trabalho, ao mesmo tempo que pode servir como um 
horizonte a ser desenvolvido em busca da construção de um direito emancipador, realizador das necessidades individuais e atento às particularidades da pessoa com deficiência.

\section{REFERÊNCIAS}

ARAUJO, Luiz Alberto David. A proteção constitucional das pessoas portadoras de deficiência. 3.ed. rev. ampl. e atual Brasília (DF): CORDE, 2003.

BRAGA, Mariana Moron Saes; SCHUMACHER, Aluisio Almeida. Direito e inclusão da pessoa com deficiência: uma análise orientada pela teoria do reconhecimento social de Axel Honneth. Soc. estado., Brasília, v. 28, n. 2, p. 375392, ago. 2013.

BISOL, Cláudia Alquati; PEGORINI, Nicole Naji; VALENTINI, Carla Beatriz. Pensar a deficiência a partir dos modelos médico, social e pós-social. Caderno de Pesquisas. São Luís, v. 24, n. 1, jan./abr. 2017.

BRASIL. [Constituição (1988)]. Constituição da República Federativa do Brasil de 1988. Brasília, DF: Presidência da República, [2020]. Disponível em: http://www.planalto.gov.br/ccivil_03/Constituicao/Constituiçao.html BRASIL. Lei 8.742, de 7 de dez. de 1993. Dispõe sobre a organização da Assistência Social e dá outras providências. Brasília/DF, dez. 1993. BRASIL. Decreto n.6.949, de 25 de ago, de 2009. Promulga a Convenção Internacional sobre os Direitos das Pessoas com Deficiência e seu Protocolo Facultativo, assinados em Nova York, em 30 de março de 2007. Brasília/DF, ago. 2009

BRASIL. Lei Complementar 142, de 8 de mai. de 2013. Regulamenta o § 1o do art. 201 da Constituição Federal, no tocante à aposentadoria da pessoa com deficiência segurada do Regime Geral de Previdência Social - RGPS. Brasília/DF, 2013.

BRASIL. Lei 13.146, de 6 de jul. de 2015. Institui a Lei Brasileira de Inclusão da Pessoa com Deficiência (Estatuto da Pessoa com Deficiência). Brasília/DF, jul. 2015.

BRASIL. Lei 13.467, de 13 de jul. 2017. Altera a Consolidação das Leis do Trabalho (CLT), aprovada pelo Decreto-Lei $n^{0} 5.452$, de $1^{0}$ de maio de 1943, e as 
Leis n o⒍019, de 3 de janeiro de 1974, 8.036, de 11 de maio de 1990, e 8.212, de 24 de julho de 1991, a fim de adequar a legislação às novas relações de trabalho. Brasília/DF, jul. 2017.

CANGUILHEM, Georges. O normal e o patológico. 6. ed. Rio de Janeiro: Editora Forense Universitária, 2009.

COSTA, Sandra Morais de Brito. Dignidade humana e pessoa com deficiência: aspectos legais trabalhistas. São Paulo: LTr, 2008.

FÁVERO, Eugênia Augusta Gonzaga. Direitos das pessoas com deficiência: garantia de igualdade na diversidade. 3. ed Rio de Janeiro: WVA Ed., 2012.

FÁVERO, Eugênia Augusta Gonzaga (organizadora); RAMOS, André de Carvalho (org.). Ministério público, sociedade e a lei brasileira de inclusão da pessoa com deficiência. [Brasília, DF]: ESMPU, 2018.

FRASER, Nancy. Da Redistribuição ao Reconhecimento? Dilemas da justiça na era pós-socialista. In: Jessé Souza. Democracia hoje: novos desafios para a teoria democrática contemporânea. Brasília: Unesp, 2001.

FRASER, Nancy. Reconhecimento sem ética? São Paulo: Lua Nova, 2007.

FRASER, Nancy; HONNETH, Axel. ¿Redistribución o reconocimiento?: un debate político-filosófico. Madrid: Morata, 2006.

GIORDANO, Blanche Warzeé. (D)eficiência e trabalho: analisando suas representações. São Paulo: Annablume: Fapesp, 2000, p. 21-41.

HONNETH, Axel. Luta por reconhecimento: a gramática moral dos conflitos sociais. 2.ed São Paulo: Ed. 34, 2009.

HONNETH, Axel. Trabalho e reconhecimento: tentativa de uma redefinição. Revista Civitas, Porto Alegre, v.8, n.1, p. 46-67, jan./abr. 2008.

HONNETH, Axel. O direito da liberdade. São Paulo: Martins Fontes, 2015. 
HONNETH, Axel. Reificação: um estudo de teoria do reconhecimento. São Paulo: Editora Unesp, 2018.

LEITE, Flávia Piva Almeida. Comentários ao Estatuto da Pessoa com

Deficiência. São Paulo Saraiva Educação 20161 recurso online.

MARTINS, Adalberto; WAITMAN, Helena Silveira A. Os trabalhos das pessoas com deficiência e a Lei n⿳⺈⿴囗十 $\mathbf{1 3 . 1 4 6 / 2 0 1 5}$. Revista Síntese Trabalhista e Previdenciária, São Paulo, v.27, n. 319, p. 9-24, jan. 2016.

ORGANIZAÇÃO DAS NAÇÕES UNIDAS (ONU). Convenção sobre os direitos das pessoas com deficiência. Disponível em:

$<$ http://www.pcdlegal.com.br/c/onvencaoonu/wp-

content/themes/convencaoonu/downloads/ONU_Cartilha.pdf.> Acesso em: 18 dez. 2019.

RUBIN, Fernando. Previdência e processo: a pessoa com deficiência e os desafios de reconhecimento judicial dos seus novos direitos. Revista Síntese Trabalhista e Previdenciária, São Paulo, v.27, n. 319 , p. 25-32, jan. 2016.

SASSAKI, Romeu Kazumi. Inclusão: construindo uma sociedade para todos. Rio de Janeiro: WVA, 1997.

SILVA, Diego Nassif da. Inclusão das pessoas com deficiência no mercado de trabalho: o conceito de pessoa com deficiência e sua aplicação jurídica. Curitiba: Juruá, 2013.

SILVA, Josué Pereira da. Nota sobre o conceito de "reformas revolucionárias" de André Gorz. Cad. CRH, Salvador, v. 30, n. 81, p. 507-522, dez. 2017.

Disponível em <http://www.scielo.br/scielo.php?script=sci_arttext\&pid=S010349792017000300507\&lng=pt\&nrm=iso>. Acesso em: 15 dez. 2019.

SOUSA JÚNIOR, Ariolino Neres. Neoescravidão urbana: condições laborais degradantes de trabalhadores com deficiências no setor terciário. Revista Bonijuris, Curitiba, v.24, n.586, p. 33-41, set. 2012.

TAYLOR, Charles. Multiculturalism: examining the politics of recognition. New Jersey: Princeton, 1994. Disponível em: 
$<$ http://elplandehiram.org/documentos/JoustingNYC/

Politics_of_Recognition.pdf>. Acesso em: 15 dez. 2019.

WANDELLI, Leonardo Vieira. O direito ao trabalho como direito humano e fundamental: elementos para sua fundamentação e concretização. 2009. 431f. Tese (doutorado) - Universidade Federal do Paraná, Setor de Ciências Jurídicas, Programa de Pós-Graduação em Direito. Disponível em:

http://hdl.handle.net/1884/20912. Acesso em: 15 dez. 2019. 